\section{New website for Manchester clinic}

The Centre for Oral, Maxillofacial and Dental Implant Reconstructive Surgery in Manchester has just launched a brand new website to provide useful information and guidance for patients and professionals.

An international ZAGA Centre located in Manchester, the clinic offers highly complex and comprehensive implant treatment utilising carefully developed clinical protocols. The team is led by
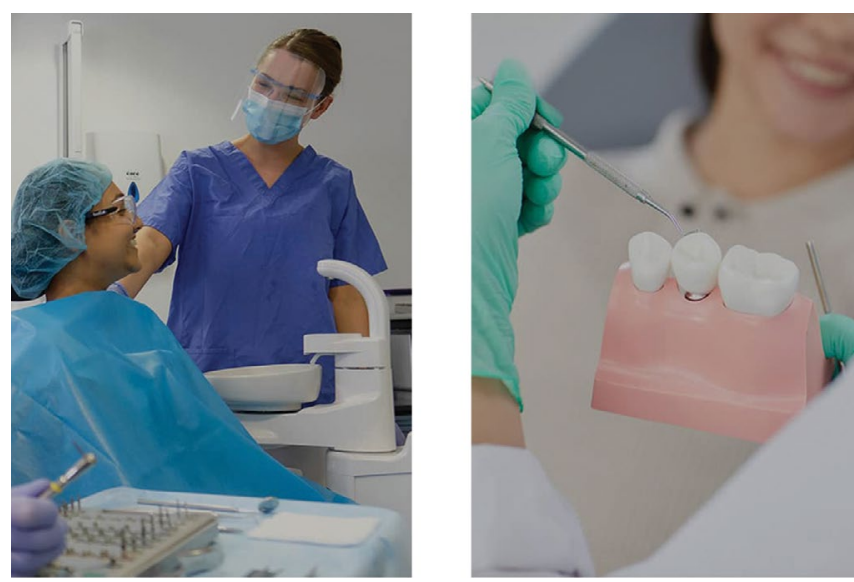
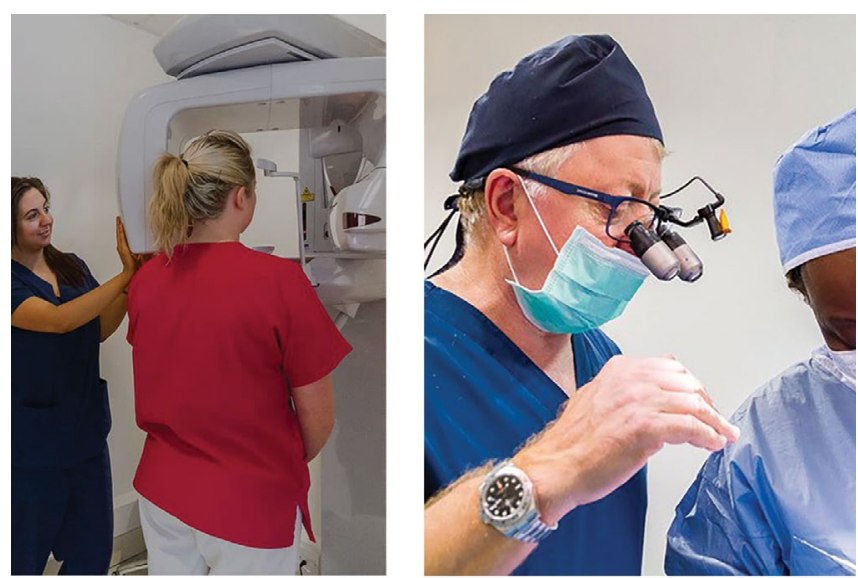

Professor Cemal Ucer, a highly-respected Specialist Oral Surgeon, lecturer and mentor. The new website introduces the clinic and demonstrates the full range of services available by referral. There are also details on fees and information specifically for patients.

If you are looking for a trusted partner to refer advanced implant cases to, visit the new website for the Centre for Oral, Maxillofacial and Dental Implant Reconstructive Surgery today.

https://ucer-clinic.dental

\section{Buffing the teeth to a beautiful smile}

For a whiter and brighter smile in just 14 days, Arm \& Hammer WHITENING PRO PROTECT toothpaste can lighten the teeth by up to three shades in six weeks, when used twice a day.

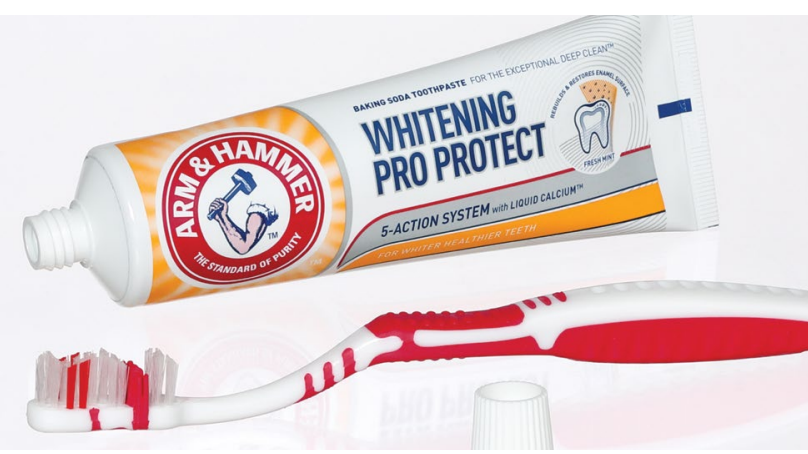

\section{Visors that accommodate your loupes}

Are you looking for a visor that enables you to wear your dental loupes comfortably?

Nuview offers two innovative solutions with the Nuview Headband Visor and the Nuview Loupe and Light Visor System. While the former is designed to be used with headband-mounted loupes and lights, the latter is ideal for frame-mounted loupe/light combinations.

Optimised for maximum user comfort and to comply with EN166:2001 requirements, these visors are positioned at a distance that your loupes and light can be used behind them. You can be confident they are also of a high optical quality to ensure supreme clarity.

For more information call Nuview on 01453 872266, email info@ nuview-ltd.com or visit www.nuview.co.uk.
WHITENING PRO PROTECT will clean and remove surface stains, naturally. Because Arm \& Hammer toothpastes contain baking soda, they are low abrasive too, protecting the precious enamel.

Baking soda is a powerful ingredient, clinically recognised to enhance the plaque removal efficiency of toothbrushing compared to products which don't contain it. For added confidence, Arm \& Hammer toothpastes also contains Micropolisher Technology to gently buff the teeth to a beautiful shine.

Arm \& Hammer WHITENING PRO PROTECT toothpaste will get your patients' smiles noticed for all the right reasons.

For more information about the carefully formulated Arm \& Hammer toothpaste range, visit http://www.armandhammer.co.uk/ or email: ukenquiries@churchdwight.com.

Arm \& Hammer oral healthcare products are available at Boots, Superdrug, Sainsbury's, Tesco, Asda and Morrisons throughout the UK.
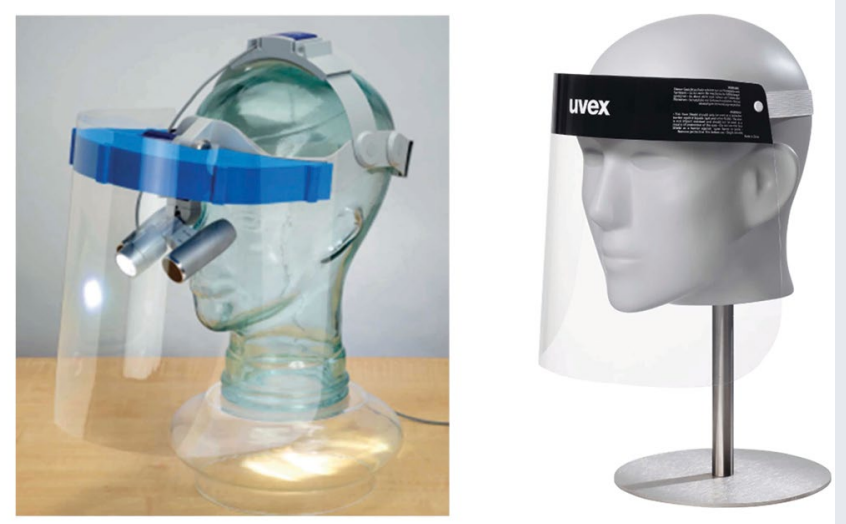